\title{
A COVID-19 e os reflexos sociais do fechamento das escolas
}

\author{
COVID-19 and the Social reflexes of school closures
}

\author{
(iD João Ferreira Sobrinho Junior \\ Doutorando em História \\ Universidade Federal de Goiás - UFG. \\ Goiânia, Goiás - Brasil. \\ joffersoju07@hotmail.com \\ Cristina de Cássia Pereira de Moraes \\ Doutora em História \\ Universidade Federal de Goiás - UFG. \\ Goiânia, Goiás - Brasil. \\ cristinadecassiapmoraes@gmail.com
}

Resumo: Esta pesquisa tem por objetivo apresentar reflexos sociais que foram acarretados pelo fechamento das escolas por conta da pandemia da COVID-19. Para responder a tal cenário, se dispôs de pesquisa bibliográfica e documental a partir de jornais, legislação e documentos oficiais, sites e artigos científicos. E como resultado percebe-se reflexos potenciais nos alunos, professores e pais, tendo em vista que problemáticas derivadas desse fechamento como: a interrupção do aprendizado; alimentação escolar; adaptação dos professores a nova realidade tecnológica; pais sem preparação para as atividades em ensino remoto e em casa; desafio na melhoria e manutenção do ensino remoto; lacunas de assistência às crianças; aumento na taxa de evasão escolar; isolamento social das crianças; e, os desafios para validar e medir o aprendizado, tendem a afetar de forma direta e indiretamente esses indivíduos, principalmente aqueles que vivem em situação de vulnerabilidade e injustiça social. Isto posto, respostas a tais reflexos sociais devem advir das relações que entremeiam o Estado-escola-aluno-família de modo que o apoio mútuo poderá dar o suporte necessário a dirimir as consequências acarretadas pelo fechamento das escolas.

Palavras-Chave: COVID-19. Educação. Vulnerabilidade social. Sociedade. Emergências de saúde pública.

Abstract: This research aims to present social reflexes that were caused by the closure of schools due to the OVID-19 pandemic. To respond to such scenario, bibliographic and documentary research was available from newspapers, legislation and official documents, websites and scientific articles. As a result, potential impacts on students, teachers and parents are perceived, bearing in mind that problems arising from this closure such as: interruption of learning; school feeding; adaptation of teachers to the new technological reality; parents without preparation for activities in remote teaching and at home; challenge in improving and maintaining remote teaching; gaps in assistance to children; increased rate of school dropout; social isolation of children; and the challenges to validate and measure learning, tend to directly and indirectly affect these individuals, especially those living in situations of vulnerability and social injustice. This said, responses to such social reflections must come from the relationships that permeate the schoolstudent-family state, so that mutual support can provide the necessary support to deal with the consequences of school closures.

Keywords: COVID-19. Education. Social vulnerability. Society. Public health emergencies. 


\section{Dialogia}

SOBRINHO JUNIOR, João Ferreira; MORAES, Cristina de Cássia Pereira de. A COVID-19 e os reflexos sociais do fechamento das escolas

\section{Introdução}

Os vírus não se propagam sozinhos, no entanto, pode ser que a natureza o leve de um lugar ao outro, mas o homem não é necessariamente o seu destino final. Dessa forma a lógica inicial é bastante simples, a abrangência e a rapidez das epidemias e pandemias seguem os passos daqueles que as portam, e em alguns casos o homem. Isso pode ser notado a partir do avanço da peste negra através da rota da seda. Também não pode ser ignorado o retorno das tropas da primeira guerra e o consequente aumento dos casos da gripe espanhola pelo mundo. E nesta pandemia, a COVID19 nos segue à espreita.

O início da pandemia Segundo Gruber (2020) começa ao final de 2019, quando rumores de um novo tipo de gripe no sudoeste asiático foi relatado a Organização Mundial da Saúde - OMS. A teoria mais aceita de sua origem estava vinculada a animais silvestres - provavelmente morcego ou pangolim - na região de Huanan na Província de Wuhan na China, mais especificamente nos mercados de animais vivos, depois estabelecido como marco zero da doença. Após um tempo este agente foi identificado como um vírus do tipo corona, então passou-se a vincular a possibilidade de uso de tratamentos já adiantados para outros coronavírus como no caso da Síndrome Respiratória Aguda Grave - SARS e da Síndrome Respiratória do Oriente Médio - MERS (LIMA, 2020).

No entanto, esse novo vírus começa a se propagar rapidamente pelo mundo e em 30 de janeiro a OMS considera a doença como uma Emergência de Saúde Pública de Importância Internacional (ESPII) ${ }^{1}$, sendo historicamente apenas a sexta sob essa condição e a segunda a ser estabelecida como pandemia ${ }^{2}$, pois no ano de 2009 a H1N1 chamada de gripe suína também foi considerada como tal. A partir disso, a escalada do contágio do novo coronavírus - como era chamado - começou a influenciar nos estabelecimentos escolares, comércio e tráfego internacional de pessoas (OPAS, 2020), ainda mais levando-se em conta que estamos em uma sociedade onde a velocidade de interação entre os indivíduos de diferentes lugares do mundo pode-se dar em questão de poucas horas, e nesse cenário uma propagação em nível mundial torna-se questão de tempo. E não tardou a acontecer.

Em 11 de fevereiro de 2020, o Grupo de Estudos de Coronavírus do Comitê Internacional de Taxonomia de Vírus nomeia o vírus como SARS-Cov-2 que significa Severe acute respiratory syndrome-related coronavirus (GORBALENYA, 2020), e logo após a doença também é nomeada, passando a chamar-se COrona VIrus Disease - COVID. Para compor o nome da doença adicionou-se o ano de seu surgimento, sendo assim estabelecida COVID-19. Essa nomenclatura é adotada com base a se desvincular de uma localização geográfica, um animal, um indivíduo ou um 
grupo de pessoas, além de que o termo fosse pronunciável e relacionado à doença (OPAS, 2020). Assim nomenclaturas como a da gripe espanhola caem em desuso por trazer questões de nível xenófobo, político, racista ou assemelhados. Então, o desconhecido patógeno passa a se chamar SARS-CoV-2, em português conhecido por Síndrome Respiratória Aguda Severa e a doença causada por ele é a COVID-19. Devido então a gravidade da escalada da COVID-19, pesquisas avançam no início de 2020 no mundo inteiro para o combate rápido a esse novo vírus do sistema respiratório sob várias facetas como: transmissibilidade, permanência ativa em ambientes fora do hospedeiro, letalidade, morbilidade, dentre outros.

Após o aparecimento da COVID-19 o cotidiano não foi o mesmo ao redor do mundo, pois, o medo e a angústia, o choro e a dor foram o dia-a-dia midiático. A surpresa e as consequências iniciais da COVID-19 foram bem sintetizadas por Bittar (2020) quando diz:

\begin{abstract}
A erupção do vírus surge, no século XXI, como a explosão de um vulcão. A princípio, a expansão da contaminação na China. Depois, na Itália. Em seguida, Espanha, França, etc. e Brasil. De forma cataclísmica, o vírus se espalha, gerando contaminação, e, espantosamente, faz o mundo parar. Em seguida, começam as fortes oscilações nas bolsas de todo o mundo, a depressão dos mercados e a desaceleração econômica. Afinal, começam as medidas de quarentena compulsória, de fechamento de fronteiras, de impedimento internacional de circulação de pessoas, até chegarmos às políticas setoriais compensatórias propostas pelos governos, como forma de lidar com os efeitos econômicos imediatos da disseminação do vírus, com riscos à saúde e à vida para milhões de pessoas, em todo o mundo. Para muitos, a única explicação possível vem à carreira do fatalismo fanático, e se proliferam as visões apocalípticas com as quais o 'fim do mundo' vem sendo invocado. (BITTAR, 2020, on-line).
\end{abstract}

Assim, as rotinas cotidianas foram mudadas ao redor do mundo, e com isso ações diversas foram implementadas com fins a evitar a propagação da doença, e dentre elas o distanciamento social que em suma pode ser delimitado como:

\footnotetext{
Distanciamento social é a diminuição de interação entre as pessoas de uma comunidade para diminuir a velocidade de transmissão do vírus. É uma estratégia importante quando há indivíduos já infectados, mas ainda assintomáticos [...], que não se sabem portadores da doença e não estão em isolamento. Esta medida deve ser aplicada especialmente em locais onde existe transmissão comunitária, [...], quando a ligação entre os casos já não pode ser rastreada e o isolamento das pessoas expostas é insuficiente para frear a transmissão. [...] O distanciamento social pode ser ampliado (não se limita a grupos específicos) ou seletivo (apenas os grupos de maior risco ficam isolados - idosos, imunodeprimidos, pessoas com doenças crônicas descompensadas). (UFRGS, 2020, online).
}

O distanciamento social também foi utilizado em outras pandemias como a da gripe espanhola e da peste negra, com fins para evitar a propagação das doenças que assolavam o tempolugar, e que também acarretou no fechamento de instituições escolares (SANTOS, 2006) (REZENDE, 2009). No cenário atual, dentre os reflexos advindos do distanciamento social por conta da COVID-19, também tivemos o fechamento imediato das escolas. O fechamento abrupto 
das escolas acarretou a necessidade da adoção emergencial do ensino remoto. Esse modelo de ensino remoto é delineado por Behar (2020) como sendo:

[...] uma modalidade de ensino que pressupõe o distanciamento geográfico de professores
e alunos e foi adotada de forma temporária nos diferentes níveis de ensino por
instituições educacionais do mundo inteiro para que as atividades escolares não sejam
interrompidas. Dessa forma, o ensino presencial físico precisou ser transposto para os
meios digitais. No ensino remoto, a aula ocorre num tempo síncrono (seguindo os
princípios do ensino presencial), com videoaula, aula expositiva por sistema de
webconferência, e as atividades seguem durante a semana no espaço de um ambiente
virtual de aprendizagem (AVA) de forma assíncrona. A presença física do professor e do
aluno no espaço da sala de aula presencial é "substituída" por uma presença digital numa
aula online, o que se chama de 'presença social'. Essa é a forma como se projeta a
presença por meio da tecnologia. (BEHAR, 2020, online).

Esse ensino remoto foi adotado pelo mundo. Dessa forma o fechamento não apenas repercutiu dentro dos muros escolares, mas também impactou no contexto social ao refletir direta ou indiretamente no contexto de pais e alunos.

Esta pesquisa se apresenta a partir de uma abordagem qualitativa por meio de pesquisa bibliográfica e documental. Para Gil (2002) a pesquisa documental se aproxima muito da pesquisa bibliográfica, entretanto a discrepância se concentra na natureza das fontes, pois:

Enquanto a pesquisa bibliográfica se utiliza fundamentalmente das contribuições dos
diversos autores sobre determinado assunto, a pesquisa documental vale-se de materiais
que não recebem ainda um tratamento analítico, ou que ainda podem ser reelaborados
de acordo com os objetos da pesquisa. (GIL, 2002, p. 45).
O desenvolvimento da pesquisa documental segue os mesmos passos da pesquisa
bibliográfica. Apenas cabe considerar que, enquanto na pesquisa bibliográfica as fontes
são constituídas sobretudo por material impresso localizado nas bibliotecas, na pesquisa
documental, as fontes são muito mais diversificadas e dispersas. (idem, p. 46).

A vista disso, no que se refere a coleta, análise e discussão dos dados, foram utilizados jornais, livros, sites, documentos oficiais e artigos de periódicos com a finalidade dar a fundamentação necessária a pesquisa.

O objetivo desse trabalho é apresentar reflexos sociais que foram acarretados pelo fechamento das escolas por conta da pandemia da COVID-19. E assim para responder ao objetivo proposto, o artigo foi dividido em duas partes: fundamentação e discussão (Reflexos do Fechamento das Instituições de Ensino no Contexto Social) e as Considerações Finais. Na primeira parte, inicia-se baseado em um comparativo histórico com a gripe espanhola visando identificar semelhanças pertinentes à temática abordada. Após isso apresenta-se nove pontos concernentes aos reflexos sociais ao qual tiveram por ponto de partida o fechamento das escolas pelo mundo: a interrupção do aprendizado; alimentação escolar; adaptação dos professores a nova realidade tecnológica; pais sem preparação para as atividades em ensino remoto e em casa; desafio na melhoria e manutenção do ensino remoto; lacunas de assistência às crianças; aumento na taxa de 
evasão escolar; isolamento social das crianças; e, os desafios para validar e medir o aprendizado. Ademais, indicamos e discutimos sob cada ponto, ações que foram implementadas no Brasil sob esse cenário. $\mathrm{Na}$ segunda parte, apresentamos as considerações finais que permeiam a temática abordada, a partir dos resultados advindos desta pesquisa.

\section{Reflexos do fechamento das instituições de ensino no contexto social}

A educação é sempre um dos primeiros setores a serem impactados em momentos de crises, principalmente quando se trata de pandemias, epidemias ou surtos de grande intensidade e abrangência. Bertucci-Martins (2003) cita sobre o fechamento das escolas na cidade de São Paulo em 1918 que se encontrava sob o avanço da gripe espanhola.

O Serviço Sanitário tomava então novas medidas para tentar minimizar a propagação epidêmica: solicitava às sociedades literárias, esportivas e recreativas que suspendessem reuniões e jogos; determinava, em conjunto com a diretoria de Instrução Pública, o fechamento dos grupos (muitos transformados em postos médicos) e das escolas primárias - medida que poderia se estender às faculdades. (BERTUCCIMARTINS, 2003, p. 111, grifo nosso).

E não somente no Brasil, como também em outros pontos do mundo a Gripe Espanhola acarretou o fechamento de instituições de ensino como em São Francisco, nos Estados Unidos (CORRÊA, 2020). Assim sendo, pela história se repetiu casos análogos em épocas de epidemias ou pandemias, nos quais as instituições de ensino eram logo fechadas. A razão é simples, como afirma Correia, Luck e Verner (2020) de que:

[...] No seu conjunto, as nossas conclusões sugerem que as pandemias podem ter custos económicos substanciais, e as intervenções não farmacológicas [entre elas, o fechamento de escolas, teatros e igrejas; a proibição de reuniões públicas e funerais; a colocação em quarentena dos casos suspeitos e a restrição nos horários de abertura dos negócios] não apenas reduziram a mortalidade, mas também mitigaram as consequências econômicas adversas da pandemia. ${ }^{3}$ (CORREIA, LUCK e VERNER, 2020, p. 1, grifo nosso).

A partir desses dados já percebemos a importância do fechamento das instituições de ensino em época de pandemias ou epidemias com a finalidade primeira de proteger vidas, no entanto, protegendo as vidas também se protege a economia. Conquanto, o que fazer com os alunos com as escolas paradas? E quais são os reflexos sociais diretos? E quanto ao retorno, como fazer? Citamos por exemplo que nos tempos da gripe espanhola no Brasil, o presidente Delfim Moreira (BRASIL, 1918) aprovou todos os alunos para o ano ou série seguintes ao promulgar o Decreto $n^{\circ} 3.603$ de 11 de novembro de 1918. Acerca desse tempo, não se encontrou dados sobre como se deu o acompanhamento dos alunos durante a gripe espanhola, no entanto levando-se em conta o caos em que as principais cidades brasileiras se encontravam, é provável que os alunos não 
tiveram o suporte das autoridades da educação em nenhum de seus níveis. Contudo, isso requer uma pesquisa mais específica e aprofundada, para verificarmos e validarmos tal hipótese. Na atual pandemia, praticamente todos os países adotaram algum tipo de restrição no que se refere às instituições de ensino como afirma Pujol (2020) quando diz que em determinado período o fechamento das escolas afetou mais de 1,5 bilhão de estudantes, ou seja, 91\% do total dos estudantes do mundo, algo inédito na história.

Esses fechamentos levantam desafios aos gestores de como realizar o acompanhamento fora da sala de aula com o apoio aos pais, professores e alunos. Segundo Unesco (2020) o fechamento de instituições de ensino ocasiona um custo adicional tanto social quanto econômico para o grupo inserido naquela realidade. Todavia, os reflexos são maiores naquelas regiões que os aspectos socioeconômicos são mais vulneráveis, extrapolando assim as desigualdades existentes dentro dos muros da escola, e ocasionando situações como:

1. Interrupção do aprendizado;

2. Alimentação escolar;

3. Adaptação dos professores a nova realidade tecnológica;

4. Pais sem preparação para as atividades em ensino remoto e em casa;

5. Desafio nas melhorias e manutenção do ensino remoto;

6. Lacunas de assistência as crianças;

7. Aumento na taxa de evasão escolar;

8. Isolamento social das crianças;

9. Desafios para validar e medir o aprendizado. (UNESCO, 2020, on-line, adaptado).

Assim destacaremos cada ponto para entendermos melhor os reflexos advindos desta pandemia na educação. O primeiro item cita a interrupção do aprendizado. Este é um sério problema aos alunos, tendo em vista que ao se fechar as escolas, diminuem consideravelmente as oportunidades de crescimento e desenvolvimento da criança. Essa interrupção é mais sentida naquelas famílias mais desprovidas, pois as crianças têm menos oportunidades educacionais fora da escola. Sob esse contexto Brito, Arruda e Contreras (2015) nos dizem que:

Em classes menos favorecidas a baixa renda familiar tem como consequência [...], a
maioria dessas pessoas só tem contato com livros e outros bens culturais de um modo
geral quando vão para escola e veem nela a oportunidade de mudar as suas condições de
vida. No entanto, muitas vezes quando chegam à escola se deparam com um ambiente
com problemas, causados principalmente pela falta de recursos que comprometem a
infraestrutura e o trabalho educacional. (BRITO, ARRUDA e CONTRERAS, 2015, p.
18671).

Também sobre o acesso a livros, é interessante destacar o que é dito Batista (1998) em relação a utilização do livro didático no Brasil, de que esse material é o principal acesso à informação pela grande massa da população. 
Os livros didáticos parecem ser, assim, para parte significativa da população brasileira, o principal impresso em torno do qual sua escolarização e letramento são organizados e constituídos. É preciso, desse modo, conhecer melhor esse impresso que terminou por se converter na principal referência para a formação e a inserção no mundo da escrita de um expressivo número de docentes e discentes brasileiros e, consequentemente, para a construção do fenômeno letramento no país. (BATISTA, 1998, p. 531).

Assim, nota-se restrições a informação através de obras literárias e artísticas por grande parcela da população brasileira, caso tal que pode se repetir em outros países subdesenvolvidos.

No contexto da pandemia no país, as escolas fecharam suas portas em um primeiro momento, após algum tempo algumas podem ter aberto suas bibliotecas de forma pontual devido as dimensões continentais do Brasil (SOARES; SCHOEN, 2020). Porém, no panorama geral os alunos não tiveram mais acesso ao interior das escolas com fins a realizar pesquisas nas bibliotecas, como também as aulas passaram a ser por acesso remoto.

O segundo item diz respeito à alimentação na escola. Segundo Cesar e Taconeli (2020) somente em 2009 com a Lei no 11.947 é regulamentado o atendimento da alimentação escolar na rede pública em consonância a garantia do direito humano à alimentação adequada no Brasil. Assim sendo, quando se toca nesse tema se aborda duas perspectivas, a primeira é a própria possibilidade de acesso à alimentação pelos alunos e a segunda é a qualidade nutritiva e calórica. No primeiro caso, tal situação torna-se um grande problema nas regiões mais pobres, e no segundo, a qualidade deve ser observada.

[...] fica evidente o desafio do [Programa Nacional de Alimentação Escolar] PNAE em trabalhar simultaneamente com diversos problemas alimentares e nutricionais enfrentados pelos estudantes brasileiros, como é o caso da dificuldade de acesso a uma alimentação adequada e o excesso de peso, por exemplo. No caso de países mais pobres, a preocupação por vezes é exclusiva e a alimentação escolar pode se apresentar como a única refeição regular e nutritiva que os estudantes têm acesso. (CESAR, TACONELI, et al., 2020 , p. 985-986).

A importância da alimentação escolar é reforçada quando se pensa em época de férias escolares como é destacado por Idoeta e Sanches (2019) acerca da vulnerabilidade social que muitas famílias enfrentam no país.

\footnotetext{
As férias escolares - quando muitas crianças deixam de ter o acesso diário à merenda intensificam a vulnerabilidade social de muitas famílias em todo o país. Embora variem em conteúdo e qualidade - às vezes são apenas bolacha ou pão, em outras, são refeições completas de arroz, feijão, legumes e carne - as merendas ocupam função importante no dia a dia de certos alunos. Para essas crianças, nos períodos sem aulas é que a fome, uma ameaça ao longo de todo ano, se torna uma realidade a ser enfrentada. (IDOETA e SANCHES, 2019, on-line).
}

E levando-se em conta que em época de pandemia o fechamento das instituições de ensino pode perdurar mais tempo do que apenas as férias regulares, pois se no curto tempo das férias esta pode ser aterrorizante para as crianças que vivem sob a intermitência de situações de fome, uma 


\section{Dialogia}

SOBRINHO JUNIOR, João Ferreira; MORAES, Cristina de Cássia Pereira de. A COVID-19 e os reflexos sociais do fechamento das escolas

pandemia traz uma grande angustia às famílias. Nesse cenário sem alimentação escolar, crianças em situação de pobreza correm o risco de adoecer pelas consequências da fome, abandonar a escola e perder a melhor chance de escapar da pobreza (WFP, 2020).

No contexto da pandemia no país, o governo federal editou a Lei n 13.987, de 7 de abril de 2020 que altera a Lei no 11.947 de 2009 para autorizar, em caráter excepcional durante o período de suspensão das aulas em razão de situação de emergência ou calamidade pública, a distribuição de gêneros alimentícios adquiridos com recursos do PNAE aos pais ou responsáveis dos estudantes das escolas públicas da educação básica. Dessa forma, as escolas passaram a distribuição em forma de kits para os alunos matriculados o alimento que iria para a merenda escolar. No entanto, Amorim, Ribeiro Junior e Bandoni (2020) entendem que os desafios impostos nestes tempos de pandemia e suas consequências econômicas e sociais à execução do PNAE devem ser encarados, ao mesmo tempo como "um chamado para um debate mais amplo e profundo sobre o sentido e o significado da alimentação escolar num país com altos índices de insegurança alimentar” (p. 1143) como é o caso do Brasil.

O terceiro item trata da adaptação e dificuldades dos professores ao ensino remoto. Carmo e Franco (2019) expõem uma síntese de competências e saberes à prática pedagógica docente no ensino à distância. Assim, muito embora essas orientações não terem sido pensadas no contexto do ensino remoto, acreditamos que por analogia podem ser consideradas para tal.

Didático-pedagógica: Domínio tanto da disciplina ensinada quanto das possibilidades de como ensiná-la a alunos adultos por meio da mobilização de conteúdos e materiais didáticos a fim de promover a aprendizagem;

Tecnológica: Capacidade de aplicar as novas tecnologias no desenvolvimento das práticas educativas para o diálogo, a interação e a colaboração entre tutor e alunos. Conhecimento da plataforma educacional utilizada no curso para orientação de como o aluno pode melhor aproveitá-la e para antecipação de possíveis dificuldades no uso das tecnologias envolvidas;

Linguística: Habilidade para redigir e compreender textos escritos a fim de preservar as relações interpessoais no grupo e orientar o aluno no processo de construção da aprendizagem. Preparo para explorar a leitura e escrita a partir do hipertexto;

Social: Capacidade de estabelecer e manter um ambiente de ensino e aprendizagem favorável à comunicação e à interação entre seus participantes;

Aprendizagem: Conhecimento de como ocorre o aprender, quais os diferentes estilos de aprendizagem e suas possibilidades no meio online. Sensibilidade para captar comportamentos que atrapalhem a aprendizagem e para intervir na preservação do interesse do aluno;

Intercultural: Habilidade para lidar com a diversidade cultural dos alunos;

Tutorial: Abertura para receber sugestões e orientações para adaptar-se a novas situações. Capacidade de administrar a participação dos alunos no curso e fluxo de atividades docentes e administrativas. Capacidade de organizar e manter uma rotina de trabalho tutorial. Capacidade de planejamento, organização e avaliação das atividades acadêmicas. (CARMO e FRANCO, 2019, p. 6).

Em tempos de pandemia esses sete pontos que tratam das competências e saberes para a prática pedagógica docente tomam maior relevância, principalmente o que se refere a tecnologia, 
tendo em vista a necessidade urgente de adequação desses profissionais ao ensino remoto e as tecnologias que dele se fazem uso. (MACHADO, 2020).

No contexto da pandemia no país a utilização das novas tecnologias foram um desafio, refletindo assim, a baixa frequência do uso de ferramentas e plataformas digitais por parte dos professores (VAILLANT; ZIDAN; BIAGAS, 2020) muitas vezes por imperícia ou mesmo pela dificuldade de acesso a tais ferramentas. Além do que, segundo Ries, Rocha e Silva (2020) a falta do traquejo das tecnologias repercutiu na forma que esses docentes disponibilizavam - por vezes - não adequadamente o material de estudo nas ferramentas/plataformas de interação entre ele e o aluno, acarretando um possível prejuízo ao ensino aprendizagem. Isso traz a questão da necessidade da capacitação do docente no momento em que sua prática presencial deu lugar a uma prática virtual com o uso de tecnologias digitais para que essas ações contribuam no "uso das novas tecnologias e metodologias ativas na sua práxis, principalmente em casos nos quais não foi possível a habilitação prévia para substituição de aulas presenciais por aulas em meios digitais. " (RIES; ROCHA; SILVA, 2020, p. 16).

Estes pensamentos corroboram ao dito por Torres, Alves e Costa (2020) ao descreverem que a pandemia é um desafio aos docentes por conta da necessidade de adaptação dos conteúdos e dinâmicas de sala de aula presencial ao ensino remoto, sem prejuízo do processo de ensino aprendizagem. E além disso, a importância do apoio dos sistemas de ensino e as suas instituições escolares nesse cenário. Vimos então a partir de uma breve discussão acerca do item 3, que é notória as dificuldades dos docentes à sua prática pedagógica em tempos de pandemia, tendo em vista que mesmo os sete pontos destacados por Carmo e Franco (2019) fazerem parte também das atividades presenciais, a forma como se dá essas atividades em ensino remoto é diferente, trazendo com isso a necessidade de adequação do docente a esse modelo virtual.

O quarto item trata dos pais sem preparação para as atividades em ensino remoto e em casa. Nesse contexto pandêmico no qual as instituições de ensino foram fechadas, os pais passaram a ajudar os filhos nas tarefas em casa. Hodiernamente, a tecnologia contribui para esse contado através do ensino remoto, nas dificuldades de manejo dos dispositivos digitais como também sua disponibilidade ou acesso, seja por fatores econômicos ou outrem podem tornar um entrave para o aprendizado. Além disso, temos a própria dificuldade dos pais por motivos diversos (pedagógico, formativo, tecnológico e laboral) de prestarem essa ajuda a contento aos filhos, pois seja no ensino público ou no ensino particular, o que os pais estão vivenciando hoje é algo totalmente novo (OLIVEIRA, 2020). Esse pensamento é corroborado por Machado (2020) quando discorre que "para os responsáveis, que em meio a um turbilhão de atividades e preocupações, estão assumindo 
o papel de tutores e educadores de seus filhos. [pois] Muitos não fazem ideia do que fazer, estão completamente perdidos." (p. 3). Dessa forma, percebe-se as dificuldades que muitos pais possuem, não por se escusar da responsabilidade, mas sim pelos desafios que a própria situação impõe.

No contexto da pandemia no país tais cenários de despreparo formativo, imperícia no trato pedagógico e tecnológico, além de estar envolto a outras questões de cunho familiar, social ou econômico, se repetiram em muitos lares e isso reflete na saúde desses indivíduos pois "as crianças e os pais estão lidando com situações altamente estressoras que ameaçam a capacidade de enfrentamento adaptativo" (LINHARES; ENUMO, 2020, p. 6). Assim, o Estado diretamente ou indiretamente deve propor ações que visem contornar essa situação através de programas de assistência à saúde para esses indivíduos.

O quinto item traz à tona as próprias formas de relação dentro dos modelos de ensino remoto, passando pela criação, manutenção e a melhoria desse modelo de ensino. Assim, a mudança repentina do presencial para o ensino remoto apresentam enormes desafios, tanto no que tange os recursos humanos quantos técnicos. A construção de plataformas de ensino ou por aprendizagem móvel deve ser pensada para o contexto em que se deseja. Além disso, as próprias formas de interação que o aluno terá, se pela web, vídeos, podcast, gamificação, aplicativos, jogos digitais, dentre outros. Ou seja, a própria implementação tende a ser complexa e além disso, seu movimento intermitente de mudança traz a necessidade de melhorias adaptadas aos avanços tecnológicos como também as transformações sociais do público-alvo, levando-se em conta, idade, classe social, disposição geográfica, dentre outros. Dessarte, a complexidade do ensino remoto é certa, como expressa Valente (2003):

\footnotetext{
No entanto, o que transparece nas propostas de cursos ou mesmo na discussão sobre essas propostas é a ideia de que existe um único tipo de Educação a Distância, que serve a todos os propósitos. Esta solução, em geral, é apresentada como sendo capaz de produzir resultados fantásticos como alunos autônomos, criativos e com capacidade de aprender a aprender. (VALENTE, 2003, p. 142).
}

No contexto da pandemia em um país continental como o nosso as desigualdades e diferenças se sobressaem, mesmo em âmbitos menores como nos municípios é um trabalho complexo a construção desde o projeto, passando pelo desenvolvimento, sua implantação, manutenção e melhoria de modelos de ensino remoto que satisfaçam de forma plena o seu objetivo. Ademais, questões que permeiam essa infraestrutura passam também pela logística e malha viária que podem comprometer, atrasar ou mesmo inviabilizar as melhorias e manutenções necessárias, devido a recursos humanos, técnicos ou mesmo pela distância. 


\section{Dialogia}

SOBRINHO JUNIOR, João Ferreira; MORAES, Cristina de Cássia Pereira de. A COVID-19 e os reflexos sociais do fechamento das escolas

O sexto item traz a assistência à infância. Ele trata da falta de opções dos pais para deixar filhos menores quando as escolas fecham. Assim, as crianças ficam em situação de maiores riscos como uso de drogas, exploração e violência sexual e o trabalho infantil, dentre outros. Conforme Vatican News (2020) isso é um fato recorrente em surtos ou epidemias.

Durante emergências anteriores de saúde pública, as taxas de abuso e exploração infantil aumentaram. O fechamento de escolas durante o surto do vírus Ebola na África Ocidental entre 2014 e 2016, por exemplo, contribuiu para aumentar o trabalho infantil, o abandono, os casos de abusos sexuais e de gravidez na adolescência. Em Serra Leoa, os casos de gravidez na adolescência chegaram a 14.000, ou seja, mais que dobraram em comparação com o período anterior à epidemia. (VATICANNEWS, 2020, on-line).

Por conta disso, deve ser redobrado o cuidado e atenção dos pais nessas situações em que a criança fica em casa, muitas vezes sozinha. Muito embora entendamos a necessidade imprescindível do trabalho dos pais, também deve-se olhar o lado das crianças, pois estas não podem estar vulneráveis nesse hiato de tempo, sob o risco de danos maiores.

No contexto inicial da pandemia no país as ocorrências de casos em que a criança ficava sozinha em casa para os pais/responsáveis irem trabalhar aumentou consideravelmente (CABRAL, 2020). Tal situação se prorrogou mesmo após a flexibilização das atividades laborais tendo em vista que as escolas, em sua grande parte ainda continuavam fechadas (SCOGNAMIGLIO, 2020). Nesse sentido, o Estado deve dar o suporte a essas famílias para que a subsistência dessas não seja prejudicada e com isso, as crianças não fiquem em situação de vulnerabilidade.

O sétimo item versa sobre a taxa de evasão escolar. Assim sendo, é desafiador assegurar que as crianças voltem e permaneçam nas instituições de ensino após o retorno das aulas presenciais. Isto se torna crítico quando o intervalo de tempo é delongado e também sob fatores socioeconômicos graves que impuseram a criança a contribuir com a família para geração de renda. Assim, podemos destacar algumas ações para favorecer o contato com os alunos durante o tempo de interrupção das aulas, como também no retorno à escola de forma presencial.

Ações durante a interrupção das aulas presenciais:

- Assegure o acesso de todos os estudantes às atividades de ensino remoto propostas;

- Mantenha canais de comunicação abertos com os estudantes e as famílias para obtenção de feedbacks sobre a atuação da escola e identificação de pontos de aprimoramento;

- Envolva os pais no engajamento dos filhos nos estudos. Eles são parceiros fundamentais nesse momento;

- Desenvolva, na medida do possível, uma forma de checagem diária com cada aluno, dando especial atenção aos mais vulneráveis.

Ações na retomada das aulas presenciais:

- Realize a busca ativa dos estudantes que não voltarem a frequentar a escola;

- Defina uma forma de avaliação diagnóstica dos alunos e de que modo será realizada a recuperação dos que apresentarem defasagem de aprendizagem; 
- Estabeleça estratégias de acompanhamento dos estudantes com maior propensão a evadir;

- Procure identificar os alunos que precisam de apoio financeiro para atendimento a despesas básicas e acione recursos de outras Secretarias, como Assistência Social. (INSTITUTOUNIBANCO, 2020, on-line, adaptado).

Assim, diminuir evasão escolar é um difícil trabalho. Podemos notar essa dificuldade a partir de uma rápida busca em pesquisas presentes no Catálogo de Teses e Dissertações da Capes (2020). Nota-se que as pesquisas aumentaram com o passar do tempo, tendo sido 4, 10, 11, 33, 80 e 86, referentes aos anos de 1996, 2000, 2005, 2010, 2015 e 2018 respectivamente. Ou seja, um aumento de mais de 2 mil por cento em 20 anos. E nesse sentindo, as pesquisas que versam sobre a evasão escolar tendem continuar em alta, principalmente para compreender os resultados de aumento ou não da evasão escolar advindos dos anos pós-pandêmicos.

Isso posto, no Brasil mesmo em tempos ditos normais mostra-se desafiador tratar da evasão escolar, e ainda mais grave torna a situação ao aplicarmos ao contexto da pandemia no país - também já taxada como sindêmica ${ }^{4}$ - que persiste por vários meses influenciando no contexto familiar, social, econômico, pessoais dentre outros aspectos. Essa evasão escolar deve ser prevenida a partir do contato contínuo escola-aluno-pais, com vistas a permanência do aluno na escola com a retomada das aulas presenciais ao final do estado pandêmico.

O oitavo item diz respeito ao isolamento social das crianças. As instituições de ensino são locais de encontro, de relação social e interação entre os alunos, dessa forma estando fechada a escola e ainda mais em tempos de distanciamento social, muitas crianças ficam sem essa referência do contato com os outros, prejudicando sua aprendizagem e desenvolvimento. Sob esse item, a pedagoga Viviana de Paula em entrevista para Lacerda (2020) diz que:

“O ideal é manter a rotina, explicar o que está acontecendo e usar os recursos que a gente
já usa a nosso favor e a favor da criança com criatividade. Os recursos tecnológicos de
vídeo e voz podem solucionar as questões de ausência. No período de isolamento a
criança não consegue estar com os amigos, por exemplo. A gente sugere que seja usada
a tecnologia para manter o contato com amigos, avós, colegas, tios." (LACERDA, 2020,
on-line).

Nota-se, portanto, que à criança é necessário o contato com os colegas de aula, vizinhos e amigos. Essas interações são mitigadas nesses tempos de pandemia com o suporte da tecnologia, pois ela é utilizada para abrandar momentaneamente essa situação, mas não supre a relação estabelecida de forma pessoal.

No contexto de uma situação de pandemia prolongada esta pode afetar a saúde mental da criança, dessa forma isso deve ser um ponto de atenção pois criança é uma população vulnerável (LINHARES; ENUMO, 2020). Tal pensamento é corroborado por Nehab (2020) ao citar que "a 
intensidade do distanciamento social, a qualidade das relações familiares e o tempo de duração deste isolamento são variáveis importantes na avaliação dos prejuízos emocionais dessa medida" (p. 22). Nesse direcionamento, o Estado deve se posicionar ao disponibilizar instrumentos e ações que visem diminuir ocorrências desse tipo, se for o caso através de programas de assistência à saúde à essa população vulnerável.

O nono e último item visa atender em como se medir e validar o aprendizado do aluno em um ambiente de ensino remoto. Assim, quando a escola fecha, se torna necessário estabelecer a forma de avaliação do aluno, pois ele deve estar estimulado e saber se ele está realmente apreendendo o conhecimento que ele está acessando. Porém, a avaliação ainda é vista sob aspectos variados como destaca Cavalcante e Mello (2015) ao dizerem que:

\begin{abstract}
Enquanto uns a enxergam [a avaliação] como instrumento de controle para forçar o aluno a estudar, outros a distinguem como estratégia essencial à qualidade do ensino e a formação profissional. Contata-se à avaliação como instrumento de punição para aqueles alunos que, por um ou outro motivo, não conseguiram chegar ao ponto esperado pelo professor. Qualifica-se a avaliação como atividade necessária no planejamento do ensino, na orientação da gestão pedagógica e no desenvolvimento institucional, mas ainda não se consegue fazer dela uma ferramenta apropriada para diagnosticar as deficiências do ensino e suas implicações na aprendizagem. (CAVALCANTE; MELLO, 2015, p. 423).
\end{abstract}

Assim, mesmo em um contexto presencial a abordagem da avaliação se apropria de pensamentos conflitantes, muito embora de forma geral a avaliação é uma temática que há muito vem sendo pesquisada na academia com fins a avaliar/mensurar o hiato que há entre o "movimento contraditório entre aprender e avaliar" (CAMARGO, 1997, p. 283). Isto posto, em um cenário de avaliação virtual este tema tem muito a ser discutido.

O contexto da pandemia no país revelou o tão sensível é se tratar de avaliação. Destacamos à priori o Parecer 005/2020 (MEC, 2020) que respondeu a necessidade da organização do calendário escolar e a possibilidade de cômputo de atividades não presenciais para fins de cumprimento da carga horária mínima anual, em razão da Pandemia da COVID-19 nas instituições de ensino no Brasil, e que foi homologado parcialmente em 28.04.2020 no Diário Oficial da União - DOU. Esse normativo teve dentre os trechos vetados, pontos que tratavam de avaliação. Ao final o Parecer $\mathrm{CNE} / \mathrm{CP} \mathrm{n}^{\circ}$ : 5/2020 foi retificado pelo $n^{\circ}$ : 9/2020 e homologado sem vetos no DOU do dia 09.07.2020. Nota-se então que mesmo em nível de normativa legal esse tema encontra dificuldades. No contexto do ensino na pandemia, a avaliação remota também é um desafio, pois o acompanhamento dessas avaliações deve ser compatível com esse modelo de ensino no qual o processo de aprendizagem se dá aos alunos em lugares e tempos diversos. (PASINI; CARVALHO; ALMEIDA, 2020). 
Um estudo interessante foi realizado pelo Centro de Inovação para a Educação Brasileira $\mathrm{CIEB}^{5}$ (2020) no início de abril de 2020. O estudo foi nomeado de "Planejamento das Secretarias de Educação do Brasil para Ensino remoto" e tinha a finalidade de verificar a situação estrutural das secretarias de educação do Brasil (estadual e municipal) frente aos novos desafios apresentados pelo ensino remoto nos tempos da pandemia. Nesse estudo, dentre os dados levantados destacamos o que questionava as secretarias municipais e estaduais se estas possuíam instrumentos que permitiam ou permitiriam futura avaliação das atividades e controle de presença dos alunos. $\mathrm{O}$ resultado obtido mostrou que $90 \%$ das secretarias municipais e $80 \%$ das secretarias estaduais, não possuíam tal instrumento. Ademais, Ganzer, Kercher e Köhnlein (2020) destacam que a avaliação realizada em tempos de pandemia por meio do ensino remoto não se distingue dos modelos tradicionais em sala de aula, pois constata-se que basicamente se estruturam na avalição classificatória e excludente.

[...] a avaliação nos tempos atuais está se consolidando quase que forçadamente a ratificação do status quo classificatório e excludente. A linha tênue entre igualdade e equidade não é transversalizada, uma vez que a readequação da ação educativa intencionada (tal qual das avaliações de aprendizagem) para o ensino híbrido/on-line enalteceu as desigualdades sociais). (GANZER; KERCHER; KÖHNLEIN, 2020, p. 231).

Assim, refletimos sobre formas diversificadas e mais atrativas para obtermos a avaliação do aluno inclusive com sua participação podem ser saídas interessantes, e não apenas reproduzir-se formas de avaliação classificatória e excludente presente no ensino tradicional, tendo em vista o conturbado momento atual de isolamento social que impôs o ensino remoto por conta da pandemia da COVID-19.

\section{Considerações finais}

No sentido de trazer ao leitor as considerações finais à pesquisa realizada, retomamos o objetivo da investigação que se propôs apresentar reflexos sociais que foram acarretados pelo fechamento das escolas por conta da pandemia da COVID-19. Por meio da pesquisa realizada identificamos nove pontos que impactaram direta ou indiretamente alunos, professores e pais, os quais são: a interrupção do aprendizado; alimentação escolar; adaptação dos professores a nova realidade tecnológica; pais sem preparação para as atividades em ensino remoto e em casa; desafio na melhoria e manutenção do ensino remoto; lacunas de assistência às crianças; aumento na taxa de evasão escolar; isolamento social das crianças; e, os desafios para validar e medir o aprendizado.

Em relação a cada um desses nove pontos destacados, a pesquisa demonstrou que o ensino remoto pode interromper a aprendizagem do aluno, pois as crianças possuem mais oportunidades 
dentro do contexto escolar de ter acesso a capital cultural no sentido de estado objetivado ${ }^{6}$ como obras literárias e artísticas - tal qual apregoado nos conceitos de Bourdieu - do que fora da escola. Além do mais, o livro didático é o principal acesso à informação pela grande massa da população brasileira. No que se refere a alimentação, é importante destacar que ações de transferência direta dos produtos alimentícios destinados a merenda escolar é salutar, muito embora isso é apenas a ponta do iceberg para questões mais profundas que permeiam principalmente o aspecto socioeconômico das famílias.

Acerca das dificuldades de adaptação dos professores ao contexto virtual de aprendizagem, deve-se principalmente à forma na qual a pandemia impôs o ensino remoto. E para dirimir questões relativas a esse desafio, o apoio dos sistemas de ensino na formação destes profissionais é essencial com fins ao aperfeiçoamento deste na adequação ou uso das melhores práticas no contexto desse modelo de ensino. Também deve-se destacar que os pais não fiquem sem apoio adequado nestes tempos de isolamento social devido a situação estressora na qual estes passam, e assim sendo o Estado através de seus braços de assistência à saúde e educação em todas as esferas tem a obrigação de dar esse suporte, propondo ações que visem contornar essa situação.

Em relação a desafios nas melhorias e manutenção do ensino remoto, estes passam não apenas pela infraestrutura das tecnologias em si que devem estar presentes nos interiores do país, como também pela logística e malha viária que podem comprometer temporal e economicamente, inviabilizando ou atrasando assim as melhorias e manutenções necessárias. Ademais, destacamos a importância desse item pois a comunicação entre aluno e escola baseia-se no ensino remoto, pois este tornou-se padrão no ensino público atualmente. Outrossim, quanto a assistência à infância, o contexto do fechamento das escolas elevou situações em que pais saem de casa, pois necessitam sustentar a família e permite-se com isso, uma maior vulnerabilidade da criança para mazelas que grassam a sociedade como exploração e violência sexual, trabalho infantil, uso de drogas, dentre outras. O Estado nesse cenário deve dar resposta a essa situação a partir de assistência econômica a essas famílias com vistas a evitar que crianças sejam expostas a maiores riscos. Essa vulnerabilidade também é sentida na taxa de evasão escolar. A evasão no Brasil mesmo em tempos normais é um desafio e se agrava hoje por conta do longo tempo de isolamento social influenciado pelo contexto familiar, social, econômico, pessoal, dentre outros aspectos. A evasão escolar deve ser prevenida a partir do contato contínuo escola-aluno-pais, com vistas a permanência deste na escola com a retomada das aulas presenciais, após o período pandêmico.

O distanciamento social também influencia no aprendizado e desenvolvimento da criança e para dirimir temporariamente tais efeitos, a tecnologia é utilizada para o contato desses com seus 
amigos e colegas, além do mais deve-se ter o cuidado com a saúde mental da criança nesses tempos, e quanto a isso o Estado deve propor ações de promoção à saúde para este público vulnerável. E para os alunos que estão efetivamente participando do ensino remoto, a avaliação de seu aprendizado deve ser realizada. Nesse sentido, devemos refletir sobre formas diversificadas e mais atrativas inclusive com a participação do próprio aluno e não apenas reproduzir formas de avaliação classificatória e excludente, presentes no ensino tradicional.

Ademais, como observações complementares advindas desse estudo percebemos que a educação em tempos de pandemia é um dos primeiros setores que são impactados. Assim sendo, o fechamento das instituições de ensino por conta do isolamento social é prática antiga nesses cenários com fins a dirimir a propagação da doença, como foi no caso da pandemia da gripe espanhola e da peste negra. A vista disso nos dias atuais com a pandemia da COVID-19 não seria diferente, dessarte o fechamento das escolas se deu logo no início da propagação do vírus em diversas regiões do mundo ao mesmo tempo, muito embora tenha representado um alto custo socioeconômico sobre famílias das regiões afligidas. Ademais, percebe-se que aqueles que estão em maior vulnerabilidade e injustiça social são os mais afetados pelo fechamento das escolas devido a COVID-19, isto posto, os governos devem se mobilizar para atender, não somente, mas prioritariamente os indivíduos nessa situação.

Entendemos que os nossos resultados contribuem no campo da educação ao apresentar reflexos sociais que foram acarretados pelo fechamento das escolas por conta da pandemia da COVID-19, fomentando com isso discussão pertinente ao contexto no qual estamos inseridos atualmente. Em relação aos reflexos apresentados, propusemos caminhos que podem mitigar essas situações a partir das relações que entremeiam o Estado, a escola, o aluno e a família. Importante destacarmos que a educação foi impactada diretamente pelo fechamento das escolas, pois esse fato influenciou em temáticas bases no processo de ensino aprendizagem como: a formação docente; acesso dos alunos a espaços que lhe tragam o capital cultural de forma abrangente; o avanço tecnológico hodierno que tenta se inserir nas práticas escolares; o diálogo comunidade-escola; a avaliação da aprendizagem; alimentação escolar enquanto elemento de assistência social; evasão escolar, dentre outros. 


\section{Dialogia}

SOBRINHO JUNIOR, João Ferreira; MORAES, Cristina de Cássia Pereira de. A COVID-19 e os reflexos sociais do fechamento das escolas

${ }^{1}$ É um evento extraordinário que pode constituir um risco de saúde pública para outros países devido à disseminação internacional de doenças; e potencialmente requer uma resposta internacional. (OPAS, 2020).

${ }^{2} \mathrm{O}$ termo "pandemia" se refere à distribuição geográfica de uma doença e não à sua gravidade. A designação reconhece que, no momento, existem surtos de COVID-19 em vários países e regiões do mundo. (OPAS, 2020).

${ }^{3}$ Original: Altogether, our findings suggest that pandemics can have substantial economic costs, and NPIs [These include closing schools, theatres and churches; banning public meetings and funerals; quarantining suspect cases and restricting business hours] cannot only be means to lower mortality but may also have economic merits by mitigating the adverse impact of the pandemic.

${ }^{4}$ No contexto de uma epidemia sindêmica o vírus não age isoladamente, e sim é potencializado por fatores sociais e ambientais como a obesidade, diabetes, doenças cardíacas, que agravando a situação do infectado. (PLITT, 2020).

${ }^{5}$ Organização da sociedade civil, sem fins lucrativos, que apoia as redes públicas de ensino básico. (CIEB, 2020).

${ }^{6}$ Estabelece-se "sob a forma de bens culturais tais como: quadros, livros, dicionários, máquinas, que constituem indícios ou a realização de teorias ou de críticas dessas teorias, de problemáticas, etc." (Bourdieu, 1998, p. 74).

\section{Referências}

AMORIM, A. L. B. D.; RIBEIRO JUNIOR, J. R. S.; BANDONI, D. H.. V. Programa Nacional de Alimentação Escolar: estratégias para enfrentar a insegurança alimentar durante e após a COVID-19. Rev. Adm. Pública, Rio de Janeiro, v. 54, n. 4, p. 1134-1145, ago. 2020. Disponível em: $<$ http://www.scielo.br/scielo.php?script $=$ sci_arttext\&pid=S0034-

76122020000401134\&lng=en\&nrm=iso > . Acesso em: 20 nov. 2020.

BATISTA, A. A. G. Aula de Português: discurso e saberes escolares. São Paulo: Martins Fontes, 1998.

BEHAR, P. A. O Ensino Remoto Emergencial e a Educação a Distância, 2020. Disponível em: $<$ https://www.ufrgs.br/coronavirus/base/artigo-o-ensino-remoto-emergencial-e-a-educacao-adistancia/>. Acesso em: 21 nov. 2020.

BERTUCCI-MARTINS, L. M. "Conselhos ao povo": educação contra a influenza de 1918. Cad. CEDES, Campinas , v. 23, n. 59, p. 103-118, abr 2003. Disponível em:

https://doi.org/10.1590/S0101-32622003000100008. Acesso em: 20 set. 2020.

BITTAR, E. C. B. GenJuridico. Coronavirus: uma pandemia para rever as patologias sociais do cotidiano, 2020. Disponível em: <http://genjuridico.com.br/2020/04/13/coronaviruspandemia-patologias-sociais/\#_ftn1>. Acesso em: 10 mai 2020.

BOURDIEU, P. Les trois états du capital culturel (tradução: Os três estados do capital cultural. In: MARIA ALICE NOGUEIRA, A. C. Escritos de Educação (Pierre Bourdieu). Petrópolis: Vozes, 1998. p. 71-81. Disponível em: https://nepegeo.paginas.ufsc.br/files/2018/06/BOURDIEUPierre.-Escritos-de-educa\%C3\%A7\%C3\%A3o.pdf Acesso em: 02 nov. 2020.

BRASIL. Decreto n 3.603, de 11 de Dezembro de 1918. Declara promovidos ao anno ou série immediatamente superior e dá outras providências, 1918. Disponivel em:

<https://www2.camara.leg.br/legin/fed/decret/1910-1919/decreto-3603-11-dezembro-1918-

572586-publicacaooriginal-95783-pl.html>. Acesso em: 12 mai 2020. 


\section{Dialogia}

SOBRINHO JUNIOR, João Ferreira; MORAES, Cristina de Cássia Pereira de. A COVID-19 e os reflexos sociais do fechamento das escolas

BRITO, M. H. D. P.; ARRUDA, N. A. D. O. D.; CONTRERAS, H. S. H. Escola, Pobreza e Aprendizagem: Reflexões Sobre a Educabilidade. Educere - XII Congresso Nacional de Educação. Curitiba, p. 18670-83. 2015. Disponível em:

https://educere.bruc.com.br/arquivo/pdf2015/21930_10055.pdf. Acesso em: 10 mai. 2020.

CABRAL, K. OLivre. Presa por deixar os filhos em casa para trabalhar, mãe desabafa: "Foi humilhante", 2020. Disponível em: < https://olivre.com.br/presa-por-deixar-filhos-em-casa-para-trabalharmae-desabafa-foi-humilhante>. Acesso em: 22 nov. 2020.

CAMARGO, Alzira Leite Carvalhais. O Discurso Sobre a Avaliação Escolar do Ponto de Vista do Aluno. Rev. Fac. Educ., São Paulo, v. 23, n. 1-2, p. 283-302, 1997. Disponível em: https://doi.org/10.1590/S0102-25551997000100015. Acesso em: 20 nov 2020.

CAPES. Catálogo de Teses e Dissertações. 2020. Disponível em: < http://catalogodeteses.capes.gov.br/catalogo-teses/\#!/ Acesso em: 20 nov 2020.

CARMO, R. D. O. S.; FRANCO, A. P. Da docência presencial à docência online: aprendizagens de professores universitários na educação a distância. Educação em Revista, Belo Horizonte, v. 35, p. 1-29, 2019. Disponível em: http://dx.doi.org/10.1590/0102-4698210399. Acesso em: 15 ago. 2020.

CAVALCANTE, Leila Pacheco Ferreira; MELLO, Maria Aparecida. Avaliação da aprendizagem no ensino de graduação em saúde: concepções, intencionalidades, reflexões. Avaliação (Campinas), Sorocaba, v. 20, n. 2, p. 423-442, 2015. Disponível em: https://doi.org/10.590/S141440772015000200008. Acesso em: 20 nov. 2020.

CESAR, J. T. et al. Adesão à alimentação escolar e fatores associados em adolescentes de escolas públicas na região Sul do Brasil. Ciência \& Saúde Coletiva, Rio de Janeiro, v. 25, n. 3, p. 977-988, mar 2020. Disponível em: http://dx.doi.org/10.1590/1413-81232020253.10742018. Acesso em: 22 jun. 2020.

CIEB. Centro de Inovação para a Educação Brasileira. Planejamento das Secretarias de Educação do Brasil para Ensino remoto, 2020. Disponível em: < https://cieb.net.br/wp-

content/uploads/2020/04/CIEB-Planejamento-Secretarias-de-Educac\%C3\%A3o-para-EnsinoRemoto-030420.pdf>. Acesso em: 17 set. 2020.

CORRÊA, A. BBC Brasil. O que era a 'Liga Anti-Máscara', que protestava contra restrições na gripe espanhola, 2020. Disponível em: <https://www.bbc.com/portuguese/internacional-52588711>. Acesso em: 12 mai 2020.

CORREIA, S.; LUCK, S.; VERNER, E. Pandemics Depress the Economy, Public Health Interventions Do Not: Evidence from the 1918 Flu. Elsevier, v. Working Paper, p. 1, 2020. Disponível em: < https://brasil.elpais.com/economia/2020-03-30/licoes-de-1918-as-cidadesque-se-anteciparam-no-distanciamento-social-cresceram-mais-apos-a-pandemia.html $>$. Acesso em: 12 mai 2020.

IDOETA, P. A.; SANCHES, M. BBC Brasil. Sem merenda: quando férias escolares significam fome no Brasil, 2019. Disponível em: < https://observatorio3setor.org.br/noticias/brasilcriancas-que-so-tem-alimentacao-na-escola-passam-fome-nas-ferias/>. Acesso em: 13 mai 2020. 


\section{Dialogia}

SOBRINHO JUNIOR, João Ferreira; MORAES, Cristina de Cássia Pereira de. A COVID-19 e os reflexos sociais do fechamento das escolas

GANZER, R. A.; KERCHER, P. H.; KÖHNLEIN, J. T. C. A Avaliação na Educação Física: Aulas Remotas Ratificando a Tendência Atual. In: PALÚ, J.; SCHÜTZ, J. A.; MAYER, L. Desafios da educação em tempos de pandemia. Cruz Alta - RS: Ilustrações, 2020. p. 324. Disponível em: $<$ http://www.sed.sc.gov.br/documentos/ensino-89/8839-livro-desafios-da-educacao-emtempos-de-pandemia >. Acesso em: 20 nov. 2020.

GIL, A. C. Como elaborar projetos de pesquisa. 4. ed. São Paulo: Atlas, 2002.

GORBALENYA, A. Severe acute respiratory syndrome-related coronavirus: the species and its viruses-a statement of the Coronavirus Study Group, 2020. Disponível em:

<https://www.biorxiv.org/content/10.1101/2020.02.07.937862v1>. Acesso em: 10 mai 2020.

GRUBER, A. Jornal da USP. Covid-19: o que se sabe sobre a origem da doença, 2020. Disponível em: <https://jornal.usp.br/artigos/covid2-o-que-se-sabe-sobre-a-origem-da-doenca/>. Acesso em: 09 mai 2020.

INSTITUTOUNIBANCO. Observatório da Educação. Ações Durante e Pós Pandemia São Necessárias para Evitar Evasão, 2020. Disponível em:

$<$ https://www.institutounibanco.org.br/conteudo/acoes-durante-e-pos-pandemia-saonecessarias-para-evitar-evasao/>. Acesso em: 27 jun 2020.

LACERDA, N. Brasil de Fato. Especialista dá dicas para o período de isolamento social com crianças em casa, 2020. Disponível em: <https://www.brasildefato.com.br/2020/03/30/especialista-da-dicaspara-o-periodo-de-isolamento-social-com-criancas-em-casa>. Acesso em: 13 mai 2020.

LIMA, C. M. A. D. O. Informações sobre o novo coronavírus (COVID-19). Radiol Bras, São Paulo, v. 53, n. 2, p. V-VI, mar/abr 2020.

LINHARES, M. B. M.; ENUMO, S. R. F. Reflexões baseadas na Psicologia sobre efeitos da pandemia COVID-19 no desenvolvimento infantil. Estud. psicol. (Campinas), Campinas, v. 37, p. 1 14, jun. 2020. Disponível em: <http://www.scielo.br/scielo.php?script=sci_arttext\&pid=S0103166X2020000100510\&lng=en\&nrm=iso $>$. Acesso em: 20 nov. 2020.

MACHADO, P. L. P. Educação em tempos de pandemia: O ensinar através de tecnologias e mídias digitais.Revista Cientifica Multidisciplinar Núcleo do Conhecimento. São Paulo - SP, n. 6, v. 8, p. 58-68, jun 2020. Disponível em:

https://www.nucleodoconhecimento.com.br/educacao/tempos-de-pandemia. Acesso em: 21 nov 2020.

MEC. Conselho Nacional de Educação. Parecer CNE/CP N: 5/2020, 2020. Disponível em: $<$ http://www.abrafi.org.br/js/ckeditor/foto_internas/pcp005_20.pdf >. Acesso em: 16 mai 2020 .

OLIVEIRA, J. Jornal Estado de Minas. Modelo de ensino a distância é desafio durante a pandemia do coronavirus, 2020. Disponível em:

<https://www.em.com.br/app/noticia/educacao/2020/04/02/internas_educacao,1134815/mo delo-de-ensino-a-distancia-e-desafio-durante-a-pandemia-do-coronavir.shtml>. Acesso em: 13 mai 2020. 


\section{Dialogia}

SOBRINHO JUNIOR, João Ferreira; MORAES, Cristina de Cássia Pereira de. A COVID-19 e os reflexos sociais do fechamento das escolas

OPAS. Folha informativa. COVID-19 (doença causada pelo novo coronavirus), 2020. Disponível em: $<$ https: $/ /$ www.paho.org/bra/index.php?option $=$ com_content\&view $=$ article\&id $=6101$ : covid19 \&Itemid=875\#historico $>$. Acesso em: 08 mai 2020.

PASINI, C. G. D.; CARVALHO, E. D.; ALMEIDA, L. H. C. A Educação Híbrida em Tempos de Pandemia: Algumas Considerações. Observatório Socioeconômico da COVID-19 - UFMS. Santa Maria, p. 1-9. 2020.

PLITT, L. BBCNews. 'Covid-19 não é pandemia, mas sindemia': o que essa perspectiva científica muda no tratamento, 2020. Disponível em: < https://www.dw.com/pt-br/sindemia-covid-19pode-ser-mais-que-uma-pandemia/a-55273059>. Acesso em: 20 nov. 2020.

PUJOL, L. EdTech. Um guia completo sobre os efeitos do coronavirus na educação, 2020. Disponível em: $<$ https://desafiosdaeducacao.grupoa.com.br/cobertura-coronavirus-educacao/>. Acesso em: 13 mai 2020 .

REZENDE, J. M. À sombra do plátano: crônicas de história da medicina. São Paulo: Editora Unifesp, 2009.

RIES, E. F.; ROCHA, V. M. P.; SILVA, C. G. L. Avaliação do ensino remoto de Epidemiologia em uma universidade pública do Sul do Brasil durante pandemia de COVID-19. Scielo em Perspectiva, 2020. Disponível em:

https://preprints.scielo.org/index.php/scielo/preprint/download/1152/1736/1818. Acesso em: 20 nov. 2020.

SANTOS, R. A. D. O Carnaval, a peste e a 'espanhola'. Hist. cienc. saude-Manguinhos, Rio de Janeiro, v. 13, n. 1, p. 129-158, mar. 2006. Disponível em:

http://www.scielo.br/scielo.php?script=sci_arttext\&pid=S0104-

59702006000100008\&lng=en\&nrm=iso>. Acesso em: 22 nov. 2020.

SCOGNAMIGLIO, H. CanguruNews. Com flexibilização da quarentena, mas sem escolas, $14 \%$ dos pais não terão com quem deixar filhos, 2020. Disponível em: <https://cangurunews.com.br/com-quemdeixar-as-criancas/>. Acesso em: 20 nov. 2020.

SOARES, L.; SCHOEN, T. H. Medidas de prevenção à Covid-19 no retorno às aulas: Protocolos de 13 países. Scielo [preprint], 2020. Disponivel em:

<https://preprints.scielo.org/index.php/scielo/preprint/download/1082/1590/1671>. Acesso em: 20 nov. 2020.

TORRES, A. C. M.; ALVES, L. R. G.; COSTA, A. C. N. Educação e Saúde: reflexões sobre o contexto universitário em tempos de COVID-19. Scielo em Perspectiva, 2020. Disponível em: https://preprints.scielo.org/index.php/scielo/preprint/view/640/885. Acesso em: 20 nov. 2020.

UFRGS. TelesaudeRS. Q ual a diferença de distanciamento social, isolamento e quarentena?, 2020.

Disponivel em: <https://www.ufrgs.br/telessauders/posts_coronavirus/qual-a-diferenca-dedistanciamento-social-isolamento-e-quarentena/>. Acesso em: 11 mai 2020.

UNESCO. Adverse consequences of school closures, 2020. Disponivel em:

$<$ https://en.unesco.org/covid19/educationresponse/consequences >. Acesso em: 13 mai 2020. 


\section{Dialogia}

SOBRINHO JUNIOR, João Ferreira; MORAES, Cristina de Cássia Pereira de. A COVID-19 e os reflexos sociais do fechamento das escolas

VAILLANT, D.; ZIDAN, E. R.; BIAGAS, G. B. Uso de plataformas y herramientas digitales para la enseñanza de la Matemática. Ensaio: aval.pol.públ.Educ., Rio de Janeiro, v. 28, n. 108, p. 718740, set. 2020. Disponível em: https://doi.org/10.1590/s0104-40362020002802241. Acesso em: 20 nov. 2020.

VALENTE, J. A. Educação a distância no ensino superior: soluções e flexibilizações. Interface Comunicação, Saúde, Educação, Botucatu - SP, v. 7, n. 12, p. 139-142, fev 2003.

VATICANNEWS. Diretrizes do UNICEF para proteger as crianças durante a pandemia. Crianças mais vulneráveis, 2020. Disponivel em: < https://www.vaticannews.va/pt/mundo/news/202003/criancas-coronavirus-diretrizes-unicef.html>. Acesso em: 13 mai 2020.

WFP. News releases. Futures of 370 million children in jeopardy as school closures deprive them of school meals - UNICEF and WFP, 2020. Disponivel em: <https://insight.wfp.org/school-feeding-athome-95ff24a2c78>. Acesso em: 13 mai 2020.

Recebido em: 23 set. 2020/ Aprovado em: 24 nov. 2020

\section{$\underline{\text { Cite como }}$}

(ABNT NBR 6023:2018)

SOBRINHO JUNIOR, João Ferreira; MORAES, Cristina de Cássia Pereira de. A COVID-19 e os reflexos sociais do fechamento das escolas. Dialogia, São Paulo, n. 36, p. 128-148, set./dez. 2020. Disponível em: https://doi.org/10.5585/dialogia.n36.18249.

\section{American Psychological Association (APA)}

Sobrinho Junior, J. F., Moraes, C. C. P. A. (2020, set./dez.). COVID-19 e os reflexos sociais do fechamento das escolas. Dialogia, São Paulo, 36, p. 128-148.

https://doi.org/10.5585/dialogia.n36.18249. 